\title{
Monitoring disease progression in COPD patients: one step beyond!
}

\author{
Pierre-Régis Burgel ${ }^{1,2}$ \\ Affiliations: 'Service de Pneumologie, Hôpital Cochin, Assistance Publique Hôpitaux de Paris, Paris, and \\ ${ }^{2}$ Université Paris Descartes, Sorbonne Paris Cité, Paris, France.
}

Correspondence: P-R. Burgel, Service de Pneumologie, Hôpital Cochin, AP-HP, 27 rue du Faubourg St Jacques, 75014 Paris, France. E-mail: pierre-regis.burgeldech.aphp.fr

-

@ERSpublications

Variability in BODE index in COPD can inform recommendations for follow-up http://ow.ly/rV1kP

Chronic obstructive pulmonary disease (COPD) is defined by persistent airflow limitation that is usually progressive [1], and its severity has long been classified using forced expiratory volume in $1 \mathrm{~s}$ (FEV1) \% predicted. Although levels of FEV1 were often reported to predict mortality, the observation that other pulmonary and extrapulmonary variables also predicted mortality led to the development of various multidimensional indices to predict survival in COPD [2]. The BODE index, which comprises nutritional status assessed by body mass index (BMI), airflow obstruction (FEV1 \% pred), dyspnoea (using the modified Medical Research Council (mMRC) scale) and exercise capacity (6-min walking distance (6MWD)), was developed 10 years ago as a predictor of all-cause and respiratory mortality [3]. The BODE index has been externally validated in many settings and remains one of the best multidimensional tools for predicting mortality in COPD patients [2]. Surprisingly, very little data are available on longitudinal evolution of the BODE index in cohorts of COPD patients.

In this issue of the European Respiratory Journal, CASANOva et al. [4] analysed longitudinal variability of the BODE index in a hospital-based cohort of (mostly male) COPD patients. The authors used an original methodology in which subjects were categorised on the basis of their pattern of variability in BODE index over 4 years or more. Interestingly, the authors found that obtaining data of variability of yearly BODE index over 2 years was sufficient to determine impact on mortality. Thus, CASANOVA et al. [4] found that stable worsening (yearly increase of $\geqslant 1$ unit) in BODE index over 2 years was associated with poorer survival in a multivariate model including several predictors of mortality in COPD patients. When assessing the variability of individual components of the BODE index, the authors reported that a high intraindividual variability in FEV1 was found and only 10-20\% (depending on the chosen threshold) had consistent decline in FEV1 over 2 years. Importantly, pattern of FEV1 variability was unrelated to mortality. Variability in BMI and mMRC over 2 years were rather low and were also unrelated to mortality [4]. Clinically significant BMI decline (defined by the authors as a yearly loss of $1 \mathrm{~kg} \cdot \mathrm{m}^{-2}$ ) was present in a small number of patients, and variations in BMI may only marginally affect the BODE index in which BMI is categorised in two groups $\left(>21\right.$ and $\left.\leqslant 21 \mathrm{~kg} \cdot \mathrm{m}^{-2}\right)$. Dyspnoea is an important prognostic factor in COPD patients and its assessment with mMRC is recommended [1]. Because mMRC lacks sensitivity and is poorly responsive to intervention [5], it is not surprising that very few patients had consistent increase in mMRC over 2 years. However, CASANOva et al. [4] found that a stable decrease in exercise capacity, measured by a yearly decline in $6 \mathrm{MWD}$ by more than $50 \mathrm{~m}$, was a clear predictor of mortality [4]. Importantly, the stable progressive BODE index pattern remained a better predictor of mortality that the progressive $6 \mathrm{MWD}$ pattern.

For many years, the natural history of COPD was characterised by progressive airflow limitation and FEV1 decline has been considered as the single marker of disease progression [6]. However, recent data obtained

Received: Dec 052013 | Accepted: Dec 122013

Conflict of interest: Disclosures can be found alongside the online version of this article at www.erj.ersjournals.com

Copyright @ERS 2014 
in two different cohorts has shown that FEV1 decline is not invariably progressive $[7,8]$, and FEV1 is only weakly correlated with patient-related outcomes. The present study clearly underlines that monitoring only FEV1 is useless in COPD patients, as its measurement is variable overtime and provides very limited prognostic information in a given patient. It suggests that disease progression in COPD patients needs to rely on multiple dimensions [4], a proposal that was also made in a recent report evaluating longitudinal stability of the new Global Initiative for Chronic Obstructive Lung Disease (GOLD) 2011 classification [9]. The study by CASANOva et al. [4] provides, for the first time, an indication of which data needs to be obtained and how often these data should be obtained during follow-up of COPD patients. To date, recommendations for follow-up of COPD patients were based on expert opinions rather than on objective data $[1,10]$, and data by CASANOva et al. [4] are most welcome and will stimulate research on follow-up of COPD, an often neglected area in practice recommendations. For example, the updated GOLD 2011 document proposes recommendations for initial pharmacological management of COPD patients, but very little guidance is provided on how to adapt therapies during follow-up.

Several limitations need to be addressed before the proposal of CASANOVA et al. [4] can become standard of care. First, the 6MWD is mandatory for calculating the BODE index [3]. Although the 6-min walk test (6MWT) is a validated tool for measuring exercise capacity in COPD patients, technical aspects of this test have prevented its widespread use in many settings. The test needs to be performed in a $30 \mathrm{~m}$ corridor, which is not always available, and requires specific equipment [11]. Performing a 6MWT is time consuming (thus costly), especially since it is often recommended to perform two 6MWT separated by 30 min (as was done by CASANOva et al. [4]) to take into account a potential learning effect [11]. The 2002 American Thoracic Society guidelines for the 6MWT suggest that a practice test is not needed in most clinical settings because the 6MWD is only slightly higher in most patients performing a second 6MWT [11], and a practice 6MWT was not performed in a recently reported large cohort of COPD patients evaluating longitudinal changes in 6MWD [12]. Not performing a practice 6MWT may constitute one way of disseminating 6MWT for COPD patients, at least in some hospital settings. Simpler ways of measuring exercise capacity (e.g. sitto-stand test [13] and 4-metre gait speed [14]) have also been developed for COPD patients and may eventually provide useful substitutes for 6MWD. Secondly, as shown by CASANOva et al. [4], BODE index does not capture all aspects of morbidity in COPD patients: hospitalisations (i.e. severe exacerbations) and Charlson index (a composite comorbidity index) were also independent predictors of mortality. AGUSTI and MACNEE [15] have recently proposed that longitudinal monitoring of COPD patients may require integration of multiple data on disease severity, activity and impact, resembling the control panel of a plane. To date, it remains unclear which data should fit in this control panel, although data by CASANOVA et al. [4] suggest that the BODE index could be one of its components. Finally, the present data are based on longitudinal evaluation in a single cohort of patients and results will have to be replicated in multiple settings before they can be widely accepted. Further, the BODE index and its variability over time provides a useful tool for evaluation of baseline severity and for longitudinal evaluation of disease activity over a relatively short period of time, but does not discriminate for severe disease occurring early versus later in life [16].

Taking all the limitations of the present study into account, findings have to be considered as novel and will stimulate future research; for the first time, they provide a scientific basis for evidence-based recommendations on follow-up of COPD patients and move the concept of disease progression in COPD one step beyond FEV1!

\section{References}

Vestbo J, Hurd SS, Agusti AG, et al. Global strategy for the diagnosis, management and prevention of chronic obstructive pulmonary disease. Am J Respir Crit Care Med 2013; 187: 347-365.

Marin JM, Alfageme I, Almagro P, et al. Multicomponent indices to predict survival in COPD: the COCOMICS study. Eur Respir J 2013; 42: 323-332.

Celli BR, Cote CG, Marin JM, et al. The body-mass index, airflow obstruction, dyspnea, and exercise capacity index in chronic obstructive pulmonary disease. N Engl J Med 2004; 350: 1005-1012.

4 Casanova C, Aguirre-Jaíme A, de Torres JP, et al. Longitudinal assessment in COPD patients: multidimensional variability and outcomes. Eur Respir J 2014; 43: 745-753.

Jones P, Miravitlles M, van der Molen T, et al. Beyond FEV1 in COPD: a review of patient-reported outcomes and their measurement. Int J Chron Obstruct Pulmon Dis 2012; 7: 697-709.

Fletcher C, Peto R. The natural history of chronic airflow obstruction. BMJ 1977; 1: 1645-1648.

Casanova C, de Torres JP, Aguirre-Jaíme A, et al. The progression of chronic obstructive pulmonary disease is heterogeneous: the experience of the BODE cohort. Am J Respir Crit Care Med 2011; 184: 1015-1021.

8 Vestbo J, Edwards LD, Scanlon PD, et al. Changes in forced expiratory volume in 1 second over time in COPD. N Engl J Med 2011; 365: 1184-1192.

9 Agusti A, Edwards LD, Celli B, et al. Characteristics, stability and outcomes of the 2011 GOLD COPD groups in the ECLIPSE cohort. Eur Respir J 2013; 42: 636-646.

10 National Institute for Health and Clinical Excellence. Chronic obstructive pulmonary disease (updated) (CG101). http://guidance.nice.org.uk/CG101 Date last updated: May 8, 2013. Date last accessed: November 30, 2013. 
11 ATS Committee on Proficiency Standards for Clinical Pulmonary Function Laboratories. ATS statement: guidelines for the six-minute walk test. Am J Respir Crit Care Med 2002; 166: 111-117.

12 Polkey MI, Spruit MA, Edwards LD, et al. Six-minute-walk test in chronic obstructive pulmonary disease: minimal clinically important difference for death or hospitalization. Am J Respir Crit Care Med 2013; 187: 382-386.

13 Puhan MA, Siebeling L, Zoller M, et al. Simple functional performance tests and mortality in COPD. Eur Respir J 2013; 42: 956-963.

14 Kon SSC, Canavan JL, Nolan CM, et al. The 4-metre gait speed in COPD: responsiveness and minimal clinically important difference. Eur Respir J 2013 [In press; DOI: 10.1183/09031936.00088113].

15 Agusti A, MacNee W. The COPD control panel: towards personalised medicine in COPD. Thorax 2013; 68: 687-690.

16 Burgel PR, Paillasseur JL, Peene B, et al. Two distinct chronic obstructive pulmonary disease (COPD) phenotypes are associated with high risk of mortality. PLoS One 2012; 7: e51048. 